\title{
35 INVESTIGATING THE EFFECTS OF INSTALLING SAFETY CAMERAS ON MANAGING THE INCIDENTS AND THE RISK ASSESSMENTS IN SAIPA (AN ASIAN AUTOMOTIVE CORPORATION)
}

doi:10.1136/injuryprev-2012-040590w.35

${ }^{1} B$ Mahyar, ${ }^{2} \mathrm{~J}$ Abdi, ${ }^{1}$ A Minoo. ${ }^{1}$ Industrial Safety Office, Saipa Automotive Corporation, Iran; ${ }^{2}$ Monitoring Office, Saipa Automotive Corporation, Iran

Objectives In this research the effects of installing safety cameras on reducing the severity or frequency of incidents and resolving the OHSAS non-conformities were investigated.

Background The research was carried out in SAIPA Automotive Corporation, in which the number of employees exceeds 10000 people. In this company, the safety supervising is being done by the safety experts during the daily site visits, however, some negligible yet important issues may be neglected in the risk assessments. Also, the details of some incidents can be disregarded specially when there is a lack of eyewitness. By inspecting the CCTV (Closed-Circuit Television) clip of an incident, its exact cause can be determined which may avoid reoccurrence of the incident and reduce the risk level in the future. Ignoring the perfect management of the conditions, may result in lethal accidents.

Significance The monitoring systems in the workshops simplified finding out the causes of some unsafe conditions. Therefore, Fault Tree Analysis, Event Tree Analysis and Failure Mode and Effects Analysis methods can be implemented better than before.

Methods The approach was the case study of the subject by registering the recorded data for 3 months and analysing the data to extract the difference before and after applying the cameras for safety inspection. 
Outcome It was shown that using the safety cameras and watching the clips of incidents carefully, plays a major role in reducing such incidents, increasing the safety level of workshops, and improving the accuracy and repeatability of risk assessments. 